\title{
Effects of a Hydrogen Gas Environment on Fatigue Crack Growth of a Stable Austenitic Stainless Steel*
}

\author{
Kyohei KAWAMOTO**, Yasuji ODA***, Hiroshi NOGUCHI**** \\ and Kenji HIGASHIDA***** \\ ** Graduate School of Engineering, Kyushu University (JSPS Research Fellow) \\ *** Department of Mechanical Engineering Science, Kyushu University \\ 744 Moto-oka, Nishi-ku, Fukuoka-shi, Fukuoka, 819-0395 Japan \\ E-mail:oda@mech.kyushu-u.ac.jp \\ **** Department of Mechanical Engineering Science, Kyushu University

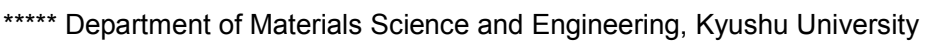

\begin{abstract}
In order to clarify the effects of a hydrogen gas environment on the fatigue crack growth characteristics of stable austenitic stainless steels, bending fatigue tests were carried out in a hydrogen gas, in a nitrogen gas at $1.0 \mathrm{MPa}$ and in air on a SUS316L using the Japanese Industrial Standards (type 316L). Also, in order to discuss the difference in the hydrogen sensitivity between austenitic stainless steels, the fatigue tests were also carried out on a SUS304 using the Japanese Industrial Standards (type 304) metastable austenitic stainless steel as a material for comparison. The main results obtained are as follows. Hydrogen gas accelerates the fatigue crack growth rate of type 316L. The degree of the fatigue crack growth acceleration is low compared to that in type 304. The fracture surfaces of both the materials practically consist of two parts; the faceted area seemed to be brittle and the remaining area occupying a greater part of the fracture surface and seemed to be ductile. The faceted area does not significantly contribute to the fatigue crack growth rate in both austenitic stainless steels. The slip-off mechanism seems to be valid not only in air and in nitrogen, but also in hydrogen. Also, the main cause of the fatigue crack growth acceleration of both materials occurs by variation of the slip behaviour. The difference in the degree of the acceleration, which in type $316 \mathrm{~L}$ is lower than in type 304 , seems to be caused by the difference in the stability of the $\gamma$ phase.
\end{abstract}

Key words: Fatigue, Hydrogen Embrittlement, Crack Propagation, Austenitic Stainless Steel, Fractography, Stability of $\gamma$ phase

\section{Introduction}

Hydrogen has been reported to decrease the strength of metals and alloys ${ }^{(1)(9)}$. An austenitic stainless steel, which is a candidate material for the components of fuel cell powered vehicles which will be marketed in the near future, has been known to be suitable for use in hydrogen. On the other hand, it has been reported that even austenitic stainless steel is embrittled in a high-pressure hydrogen gas environment ${ }^{(10)-(16)}$ or by a cathode hydrogen charge ${ }^{(17),(18)}$. In order to ensure the safety of components exposed to hydrogen gas for a long time, it is important to clarify the effects of the hydrogen environment on the fatigue strength.

*Received 27 Dec., 2006 (No. T-05-1188) Japanese Original : Trans. Jpn. Soc. Mech. Eng., Vol.72, No.722, A (2006), pp.1525-1532 (Received 21 Nov, 2005) [DOI: 10.1299/jmmp.1.263] 
There are many reports about hydrogen effects on the static tensile strength characteristics of austenitic stainless steel ${ }^{(10) \sim(13),(16),(17)}$. For example, Han et al. reported that the decrease in the fracture elongation and the reduction of area by hydrogen are strongly associated with the stability of the $\gamma$ phase ${ }^{(16)}$. It is well known that the more stable the $\gamma$ phase, the less the material is sensitive to hydrogen in the static tensile mode. On the other hand, there are some reports on the fatigue characteristics of austenitic stainless steels in a hydrogen environment including our reports ${ }^{(14),(15),(19),(20)}$. They reported the findings concerning fatigue crack growth (FCG) acceleration, the effects of the stability of the $\gamma$ phase on the degree of the acceleration, increasing of a brittle faceted area and so on. Also, some of us investigated the fatigue characteristics of a type 304 in a hydrogen gas environment and develop the phenomenon that FCG acceleration mainly occurs in ductile mode and hydrogen enhances the concentration of slip to a fatigue crack tip ${ }^{(19)}$.

The FCG characteristics of stable austenitic stainless steels in hydrogen gas environment are not sufficiently obvious, because the materials used in the above-mentioned past studies on the fatigue characteristics were metastable austenitic stainless steels. The stable austenitic stainless steels are expected to show superiour fatigue characteristics in hydrogen as is the case for the static tensile characteristics in hydrogen. It is considered difficult to estimate the material safety from investigations on the static tensile characteristics primarily concerning the formation and increase in the brittle facets because the cause of the FCG acceleration exists not only in the brittle mode but also in the ductile mode as previously mentioned. Right now, it doesn't seem obvious whether hydrogen enhances the FCG rate of stable austenitic stainless steels.

In this study, in order to clarify the effects of a hydrogen gas environment on the FCG characteristics of stable austenitic stainless steels, bending fatigue tests were carried out on a type $316 \mathrm{~L}$ in a hydrogen gas, in a nitrogen gas at $1.0 \mathrm{MPa}$ and in air. In addition, in this study, the objective concerning the level of a FCG rate is a relatively high crack growth rate (about and over $10^{-7} \mathrm{~m} /$ cycle). Also, we discuss the difference of hydrogen effects between the austenitic stainless steels by investigating the FCG characteristics of a type 304 metastable austenitic stainless steel as a material for comparison.

\section{Apparatus and Experimental Procedure}

\subsection{Testing System}

The testing apparatus used in this study is a system in which the fatigue test can be performed in a gas environment including a hydrogen gas environment ${ }^{(20)}$. This system consists of three parts; a testing machine for plain bending fatigue, an environmental chamber and an optical microscope for in-situ observation. The fatigue process can be monitored using the microscope through the glass window on the chamber. Table 1 shows the specifications of this testing system.

Table1 Specifications of testing system.

\begin{tabular}{c|c|c|c|c}
\hline performance & testing frequency & pressure range & tempareture range & magnification \\
\hline$\sim 250 \mathrm{Nm}$ & $\sim 30 \mathrm{~Hz}$ & $\sim 1.0 \mathrm{MPa}$ & R.T. $\sim 410 \mathrm{~K}$ & $\sim 84$ times \\
\hline
\end{tabular}

\subsection{Materials and Specimen}

The materials used in this study are a SUS316L by Japanese Industrial Standards (type 316L) stable austenitic stainless steel and a SUS304 by Japanese Industrial Standards (type 304) metastable austenitic stainless steel, which are solution treated. Table 2 shows the chemical compositions of both materials. The grain sizes of both materials are approximately $30 \mu \mathrm{m}$ 
Table2 Chemical compositions (mass \%).

\begin{tabular}{c|cccccccc}
\hline \hline material & $\mathrm{C}$ & $\mathrm{Si}$ & $\mathrm{Mn}$ & $\mathrm{P}$ & $\mathrm{S}$ & $\mathrm{Ni}$ & $\mathrm{Cr}$ & $\mathrm{Mo}$ \\
\hline JIS SUS316L & 0.010 & 0.63 & 1.19 & 0.031 & 0.003 & 12.13 & 17.41 & 2.05 \\
\hline JIS SUS304 & 0.046 & 0.49 & 0.84 & 0.020 & 0.005 & 8.70 & 18.42 & 0.09 \\
\hline
\end{tabular}

Hirayama et al. reported that the strain-induced $\alpha$ ' martensite phase does not generate if the $\mathrm{Ni}$ equivalent $(\mathrm{Ni})$ as described in the equation $(1)$ is over $25.7 \%{ }^{(21)}$. The Ni equivalent represents the thermodynamic stability of $\gamma$ phase of austenitic stainless steels concerning the phase transformation. As the results of the assignments of the component fraction in Table 2 into the equation (1), the values of (Ni) are $27.1 \%$ in the type $316 \mathrm{~L}$ and $22.4 \%$ in the type 304 . Thus, the type $316 \mathrm{~L}$ and 304 are considered a stable austenite and a metastable austenite, respectively.

$(\mathrm{Ni})=\mathrm{Ni}+0.65 \mathrm{Cr}+0.98 \mathrm{Mo}+1.05 \mathrm{Mn}+0.35 \mathrm{Si}+12.6 \mathrm{C} \quad[\mathrm{mass} \%]$

Figure 1 shows the shape and dimensions of the fatigue specimens. After the mechanical processes, the specimens were mechanically polished with \#2000 emery paper (emery polishing) and lapped with $0.05 \mu \mathrm{m} \gamma$-alumina dispersed on micro-cloth (buff polishing) in order to make surface plain and observations easier. Finally, a pair of small blind holes as shown in Figure 1 was introduced at the center of each specimen as a crack initiation site.

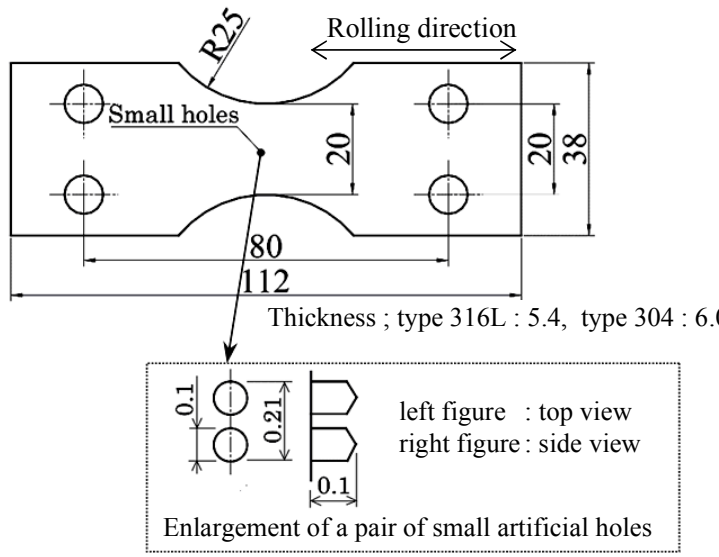

Fig. 1 Shape and dimensions (in $\mathrm{mm}$ ) of a fatigue specimen.

\subsection{Testing Method}

The fatigue tests were carried out under fully reversed plain bending with a constant amplitude angular displacement in hydrogen gas, in nitrogen gas and in air. The strain range was measured with strain gauges mounted on each specimen. The loading waveform was a sine wave. Also, the testing frequency was $5.0 \mathrm{~Hz}$.

The chamber is filled with commercially available pure dry hydrogen gas or pure dry nitrogen gas. The purity of the commercial gases is over 99.995 mass percent. The pressures of the hydrogen gas and nitrogen gas are 1.0MPa. The temperature was kept constant at 313 $\mathrm{K}$ during each fatigue test. In addition, the purpose of tests in nitrogen was an investigation of the removal effects of the air-components (oxygen, water vapour etc.). Before filling of the testing gas environment, the production of a vacuum with an oil rotary vacuum pump and the sealing a 1.0MPa nitrogen gas were alternately repeated three times.

\section{Experimental Results and Discussion}

\subsection{Hydrogen Entry Characteristics}

Investigations of the hydrogen entry characteristics were preceded the FCG tests. The 
measuring method of the hydrogen contents was thermal desorption spectrometry (TDS). The material used in this test is a type $316 \mathrm{~L}$. The samples were exposed to hydrogen gas (pressure; 1.0MPa, temperature; 393K) for 100 hours before measurement of its hydrogen content.

First, the effect of the surface condition on the hydrogen entry was investigated. Three kinds of samples were evaluated. The surface finishes are no polish (as an abrasive cut), buff-polish and electro-polish. The shape and dimensions of the samples are a thin plate of $5.0 \times 7.0 \times 0.18$ (in $\mathrm{mm}$ ). Figure 2 (a) shows the relationship between the hydrogen contents and surface finishes of the samples. The amount of the desorbed hydrogen increases in every sample. The change in the hydrogen content in an electro-polished sample is considerably lower than that in the non-polished and that in the buff-polished sample. Judging from the point of view at hydrogen entry and surface observations, the buff-polished surface is appropriate for a fatigue specimen. Thus, the buff-polished surface finishing is adopted as follows.

Next, the hydrogen content distributions of the buff-polished samples were measured using three samples having a different thickness to each other. The dimensions of the sample are $5.0 \times 7.0 \times$ thicknesses $x$ (in $\mathrm{mm}$ ), respectively. Figure 2 (b) shows the distribution of the hydrogen content in the depth direction. This diagram was obtained by the difference of the hydrogen content of the above mentioned tips. This figure indicates that hydrogen intrudes into the material interior by several hundred micro-meters under this condition of hydrogen charge. In the next section, the effect of hydrogen on the FCG rate are examined including the effect of the hydrogen pre-charging under this condition (pressure; 1.0MPa, temperature; $393 \mathrm{~K}$, time; 100hours) before the fatigue test.

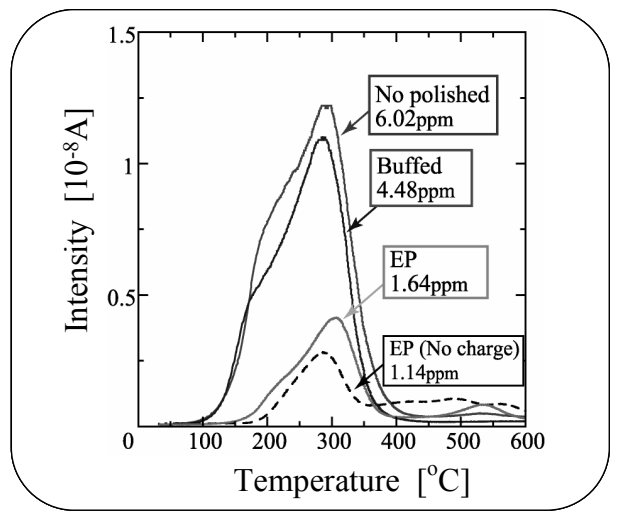

(a) Effect of surface condition on hydrogen entry.

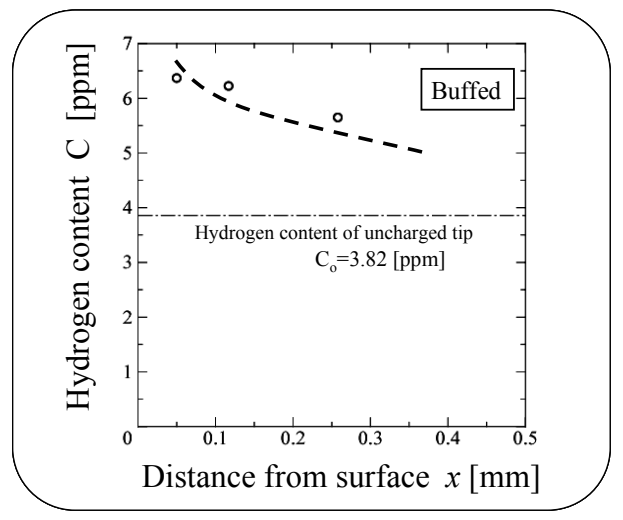

(b) Hydrogen content distribution of buffed tip.

Fig. 2 Hydrogen content of type 316L exposed to hydrogen gas.

$$
\text { ( } p=1.0 \mathrm{MPa}, T=393 \mathrm{~K}, t=100 \text { hours) }
$$

\subsection{Effects of Hydrogen Environment on Fatigue Crack Growth Rate}

In order to clarify hydrogen effects on the FCG rate, the fatigue tests were carried out in hydrogen gas at a pressure of 1.0 $\mathrm{MPa}$, in the nitrogen gas at the same pressure as the hydrogen and in air for the type 316L and the type 304.

\subsubsection{Fatigue Crack Growth Test for Type 316L Stable Austenitic Stainless Steel}

Figure 3 shows that the FCG diagram in the total strain range $\Delta \varepsilon_{t}=0.49 \% . \Delta \varepsilon_{t}=0.49 \%$ was chosen as a representative value for the relatively high FCG rate ${ }^{(20)}$. One test in hydrogen was carried out using a specimen, which was exposed to the hydrogen gas (pressure; 1.0MPa, temperature; 393K, time; 100hours) before the fatigue test. In order to 
compare the pure FCG among the three environments, this diagram shows the processes after the crack length $2 a$ reached $0.4 \mathrm{~mm}$, at which crack is considered to overcast the bottom of the twin artificial holes. In addition, in this diagram, not only the data for the type $316 \mathrm{~L}$ but also those for the type 304 presented in the next section are shown.

The fatigue cracks in hydrogen and in air grow fast compared with that in nitrogen $(\bullet / \Delta$ and $\downarrow)$. Both hydrogen gas and the components of air ${ }^{(22)}$ have effects on the FCG acceleration. $\boldsymbol{\nabla}$ in Figure 3 denotes the crack growth plots in hydrogen for the hydrogen pre-charged specimen. The effect of the exposure to the hydrogen gas on the FCG rate is little ( $\boldsymbol{\Delta}$ and $\boldsymbol{\nabla}$ ), though there is the possibility of crack growth acceleration by hydrogen pre-charge when the crack is short (Figure 2(b)). The hydrogen of the material interior doesn't seem to influence the growth rate in this case.

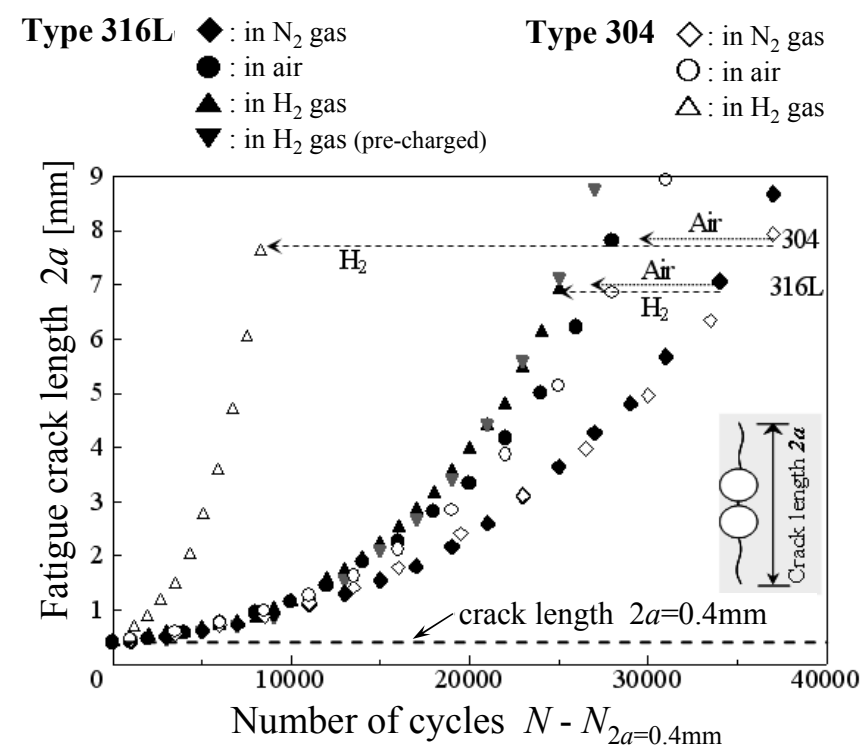

Fig. 3 Fatigue crack growth plots for type 316L and type 304.

$\left(\Delta \varepsilon_{\mathrm{t}}=0.49 \%\right.$, after crack length reached $\left.2 a=0.4 \mathrm{~mm}\right)$

3.2.2 Comparison of Degree of Fatigue Crack Growth Acceleration between Type 316L and Type 304 Stainless Steels

The FCG curves of the type $316 \mathrm{~L}$ described in the previous paragraph are compared to that of the type 304. Figure 3 shows that FCG of the type 304 is accelerated by both the hydrogen gas and the air-component as is the case with the type $316 \mathrm{~L}$. The degrees of the FCG acceleration by the air-component of both materials ( $\circ$ and $\diamond$, $\bullet$ and $\diamond)$ are almost equal, however, the degree of the acceleration by hydrogen gas in the type 304 is greater than that in the type $316 \mathrm{~L}$ ( $\Delta$ and $\diamond, \boldsymbol{\Delta} / \boldsymbol{\nabla}$ and $\diamond$ ). In the following section, the FCG rate in hydrogen is compared with that in nitrogen, because air-components have the effect of FCG acceleration.

Figure 4 shows the FCG rate in nitrogen and in hydrogen gas environment calculated from the data in Figure 3. The degree of FCG acceleration by hydrogen is nearly constant in both the materials in the range of $\mathrm{d} a / \mathrm{d} N=4 \times 10^{-8} \sim 10^{-6} \mathrm{~m} /$ cycle. The FCG rate in hydrogen is approximately 1.4 times as high as that in nitrogen in the type $316 \mathrm{~L}$ and 4.0 times as high as that in nitrogen in the type 304, respectively. The sensitivity to hydrogen gas in the range of the high FCG rate in type 316L stable austenitic steel is lower than that in type 304 metastable austenitic steel (In addition, the degree of the acceleration is low on less than the growth rate, though the hydrogen effects on such a range of the growth rate are not discussed in this paper as we already described.). 


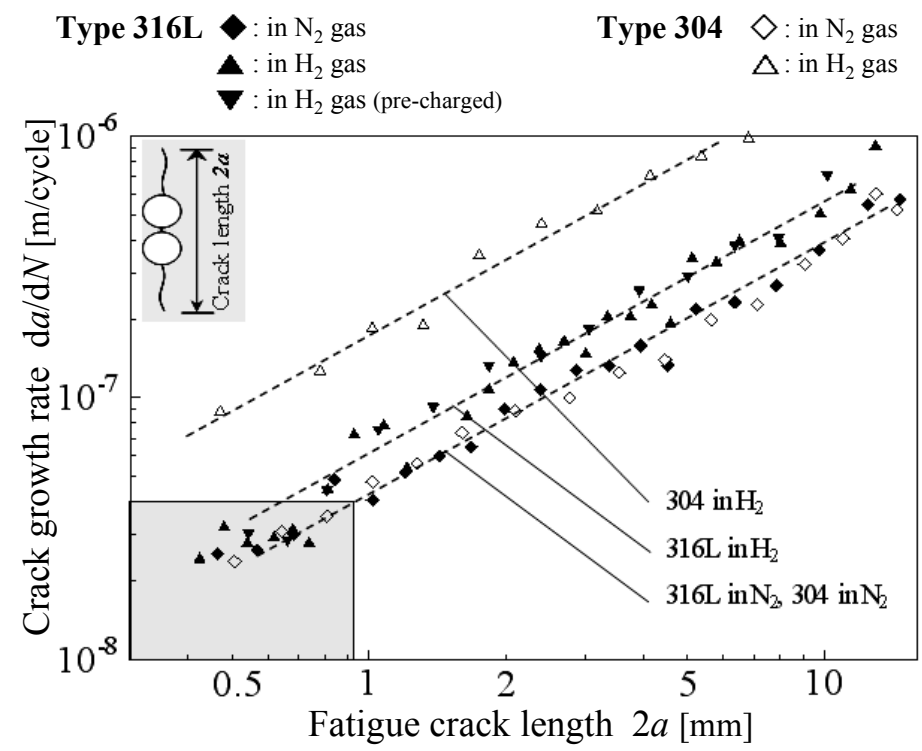

Fig. 4 Fatigue crack growth rate for type 316L and type 304. $\left(\Delta \varepsilon_{\mathrm{t}}=0.49 \%\right.$, after crack length reached $\left.2 a=0.4 \mathrm{~mm}\right)$

\subsection{Fatigue Crack Growth Characteristics in Hydrogen Environment}

To investigate the difference in the FCG characteristics in hydrogen between austenitic stainless steels, the characteristics of the type $316 \mathrm{~L}$ are compared with those of the type 304 investigated in our previous studies ${ }^{(19),(20)}$.

\subsubsection{Features of Fatigue Fracture Surface of Type 316L Stainless Steel}

Figure 5 shows macroscopic photographs of the fatigue fracture surfaces of the type $316 \mathrm{~L}$ tested at $\Delta \varepsilon_{\mathrm{t}}=0.49 \%$ with the optical microscope; (a) in nitrogen gas and (b) in hydrogen gas. The shape of each crack is clearly seen from the beach mark formed at the ligament length of either side of $2.5 \mathrm{~mm}$. The aspect ratios $(b / a)$ of both cracks are almost the same in both the environments; $b / a \approx 0.40$. The FCG acceleration by hydrogen occurs in the depth direction as is the case for the specimen surface. Therefore, it is expected that some hydrogen effects based on the acceleration are reflected on the fatigue fracture surface.

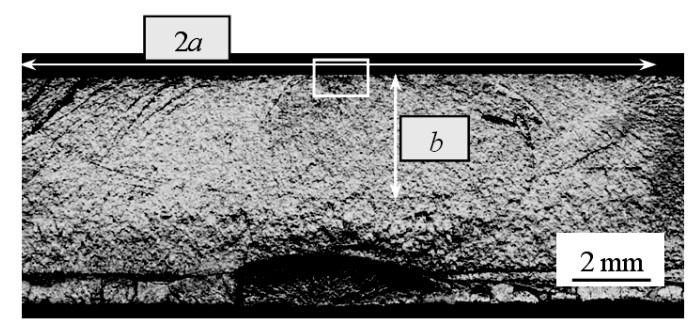

(a) in $\mathrm{N}_{2}$ gas

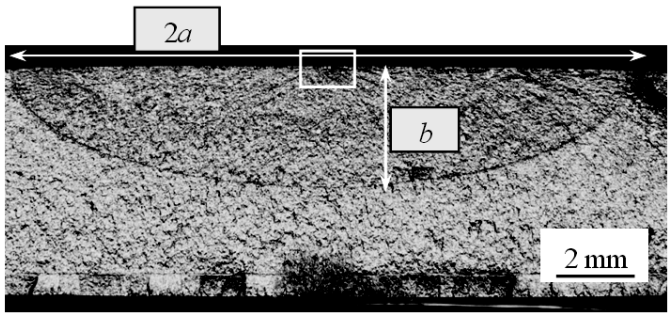

(b) in $\mathrm{H}_{2}$ gas

Fig. 5 Macroscopic images of fatigue fracture surfaces of type 316L.

(a square indicates crack origin; a pair of small artificial holes) 
Figure 6 shows SEM photographs of the fatigue fracture surfaces in nitrogen (a) and in hydrogen (b) of the type 316L at a low magnification. Figure 7 shows the enlarged photographs of each area surrounded by the dotted square in Figure 6 (a), (b). The mechanical conditions of the areas indicated by (A-1) and (B-1), (A-2) and (B-2), (A-3) and (B-3) in Figure 6 (a), (b) are nearly equal (The distances from the center of a pair of small artificial holes to the each area are $d_{1}=1.2 \mathrm{~mm}, d_{2}=2.0 \mathrm{~mm}, d_{3}=2.9 \mathrm{~mm}$. The angle of the specimen surface and the direction from the center of a pair of holes to each area is 30 degrees.). The fracture surfaces in both environments mostly consist of two parts. One is the faceted areas that seemed to be brittle (the areas indicated by arrows in the Figure 7) and the remaining part of the fracture surface is the area that seemed to be ductile. In order to clarify the hydrogen effects on the FCG rate, it is necessary to estimate the effects on the FCG concerning both fracture surfaces.

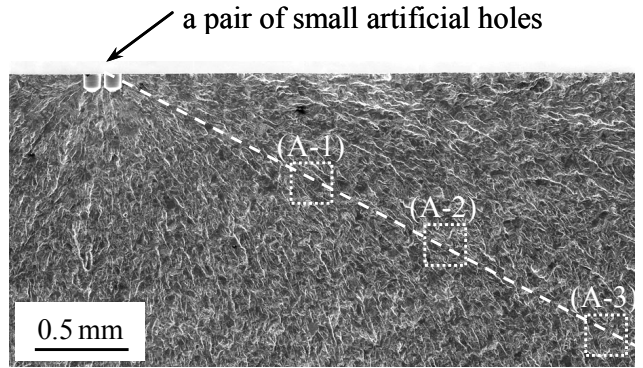

(a) in $\mathrm{N}_{2}$ gas

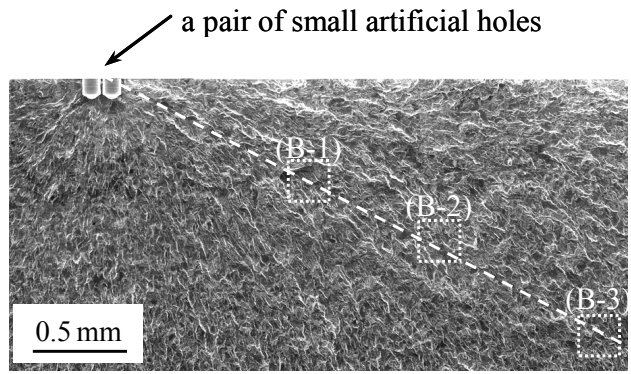

(b) in $\mathrm{H}_{2}$ gas

Fig. 6 SEM images of fatigue fracture surfaces of type 316L at a low magnification.

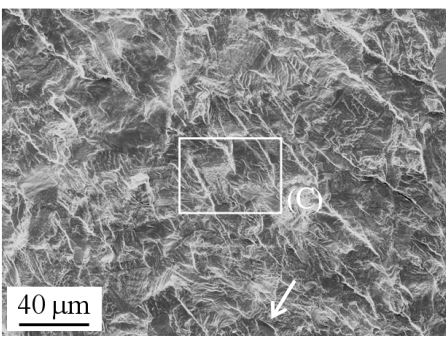

(a-1) Enlargement of (A-1)

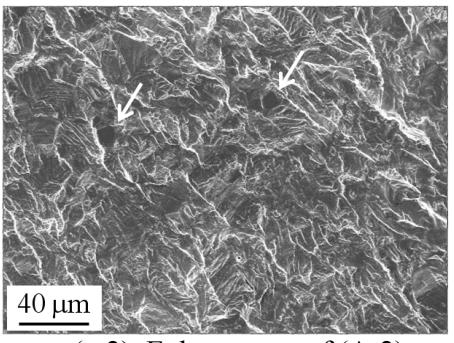

(a-2) Enlargement of (A-2)

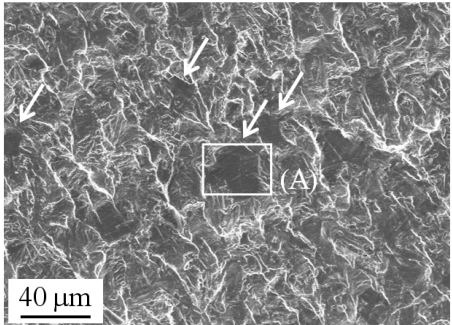

(a-3) Enlargement of (A-3)

(a) in $\mathrm{N}_{2}$ gas, Enlargement of Figure 6(a)

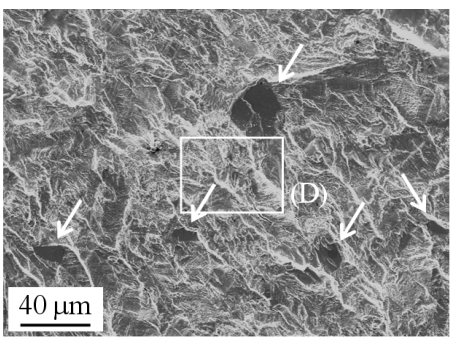

(b-1) Enlargement of (B-1)

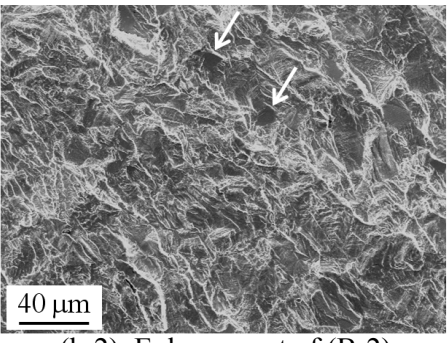

(b-2) Enlargement of (B-2)

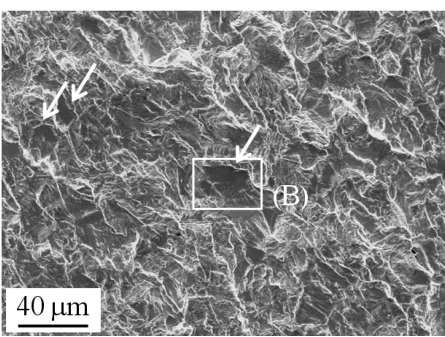

(b-3) Enlargement of (B-3)

(b) in $\mathrm{H}_{2}$ gas, Enlargement of Figure 6(b)

Fig. 7 Enlargements of fatigue fracture surfaces in Figure 6.

(An arrow indicates faceted area.) 
Figure 8 shows enlarged examples of the flat sites in Figure 7(a-3) and (b-3). Straight patterns in a direction perpendicular to the direction of propagation are observed in the flat sites. Such a facet was reported to be a grain boundary or a twin boundary or a boundary between an austenite phase and a strain-induced martensite phase ${ }^{(15),(16)}$ and generally considered to be a brittle fracture part. In the type $316 \mathrm{~L}$, the amount of the faceted area is not clearly changed in hydrogen compared to that in nitrogen as shown in Figure 7. On the other hand, in the case of metastable austenitic stainless steels, it was reported that the ratio of the faceted areas to the overall fatigue fracture surface increase at least somewhat in hydrogen ${ }^{(15),(19),(20)}$. Anyhow, the ratio is low in each environment in both materials. It was manifested that a faceted area is produced not at once but cyclically and soon after the facet, the growth rate decreases in the previous study ${ }^{(19)}$. These indicate that the faceted areas are not significantly responsible for the acceleration of the FCG. Therefore, it is considered that the accelerating effects of hydrogen mainly occur in the remaining part seemed to be ductile. On the ductile fracture surface of the type $316 \mathrm{~L}$, a lot of distinct striation patterns were observed in both the nitrogen and hydrogen environments (The examples of striation patterns are shown in the lower row of Figure 9.). Thus, the slip-off mechanism ${ }^{(23) \sim(25)}$

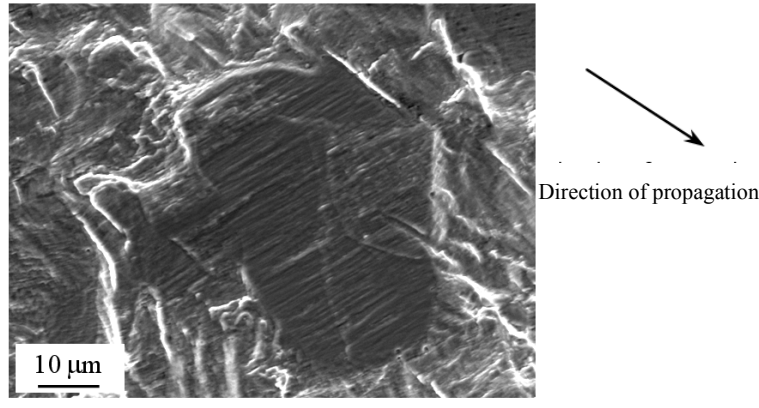

(a) in $\mathrm{N}_{2}$ gas, Enlargement of the area (A) in Figure 7 (a-3)

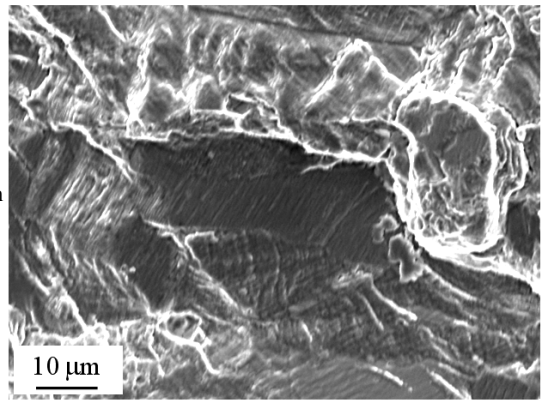

(b) in $\mathrm{H}_{2}$ gas, Enlargement of the area (B) in Figure 7 (b-3)

Fig. 8 Examples of faceted area on fracture surface.

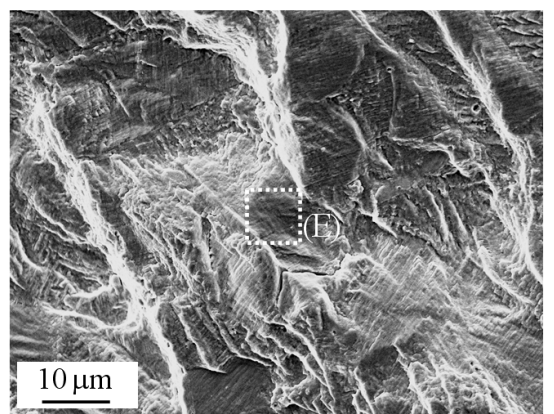

Enlargement of the area (C) in Figure 7 (a-1)

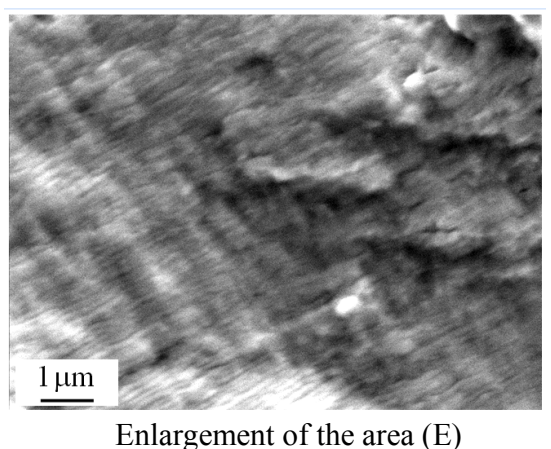

(a) in $\mathrm{N}_{2}$ gas

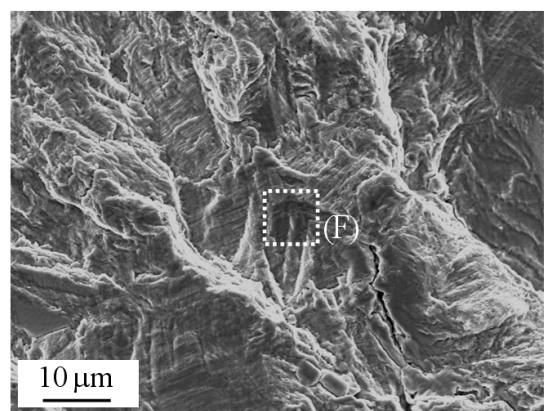

Enlargement of the area (D) in Figure 7 (b-1)

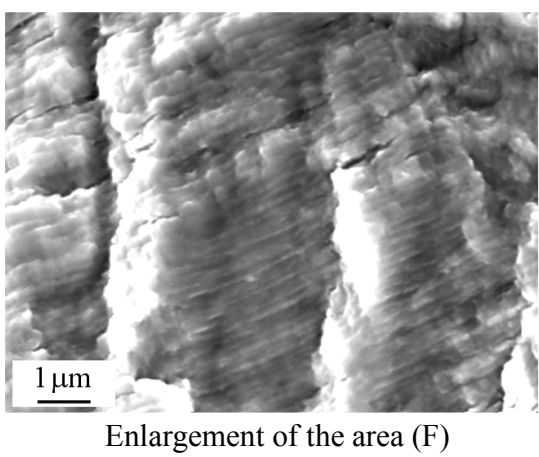

(b) in $\mathrm{H}_{2}$ gas

Fig. 9 Examples of striation patterns on ductile fracture surfaces. 
seems to be valid not only in nitrogen, but also in hydrogen. It is considered that the FCG acceleration by hydrogen occurs in the mechanism. Some of us already clarified that the slip is concentrated at a crack tip in hydrogen using the type $304^{(19)}$. Though there may be a difference in the degree between the materials, slip concentration at the crack tip is considered to occur in the case of not only the type 304, but also the type 316L.

\subsubsection{Measurement of Striation Spacing}

FCG acceleration by hydrogen is reflected in the striation spacings, because the ductile fracture mode does predominant in both environments.

Figure 10 shows the striation spacings on the fracture surface of the type $316 \mathrm{~L}$ fatigued in the nitrogen and in the hydrogen gas environment. The measured points are on a straight line as indicated by the dotted lines in Figure 6 (a) and (b). The abscissa is the distance from the center of a pair of small artificial holes to each striation patterns. The ordinate is the striation spacing. Though the striation spacings are of uneven values, those in hydrogen are wider than those in nitrogen. This result seems to support the fact that the FCG acceleration occurs in the ductile mode because the amount of the faceted area has not clearly changed between environments.

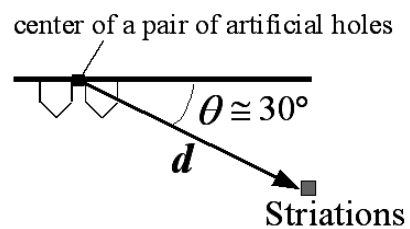

(a) Definition of distance $d$

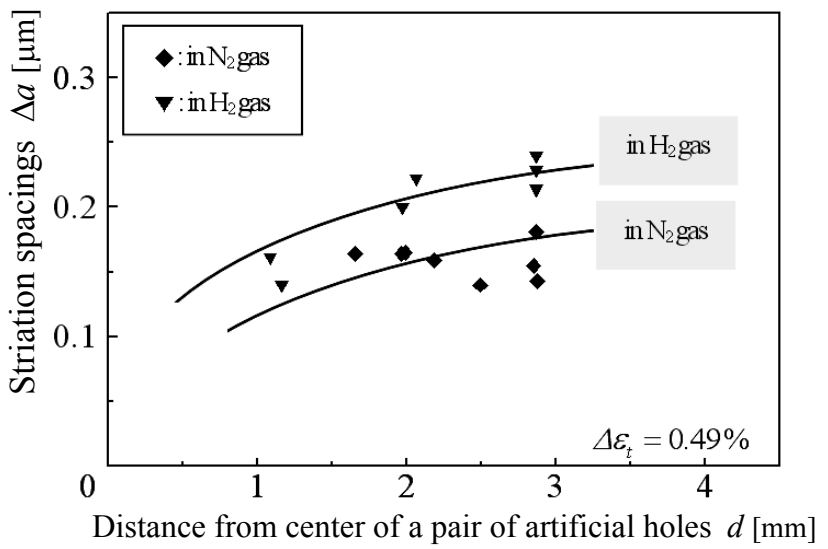

(b) Striation spacings in $\mathrm{N}_{2}$ gas and in $\mathrm{H}_{2}$ gas

Fig. 10 Striation spacing on fatigue fracture surface of type $316 \mathrm{~L}$.

$$
\left(\Delta \varepsilon_{\mathrm{t}}=0.49 \%\right)
$$

\subsection{Discussion: Comparison of Hydrogen Sensitivity on Fatigue Crack Growth Rate between Austenitic Stainless Steels}

In the previous section, based on the test result, the degree of the FCG acceleration by hydrogen in the type $316 \mathrm{~L}$ is lower than that in the type 304 , was described. In this section, this point is described by classifying it into the following two points. One point is the acceleration by increasing the brittle faceted areas. The other point has the acceleration in the ductile fracture mode.

Concerning the brittle mode, there is little difference in the amount of the faceted area between nitrogen and hydrogen in the type $316 \mathrm{~L}$. On the other hand, in the case of the type 
304 , the amount of the faceted area was greater in hydrogen than in air or the inert gas ${ }^{(15) \text {, }}$ (19), (20). Though an increase in the facets is considered to contribute to the FCG acceleration, the facets are not predominant to FCG rate due to the low ratio of facets to the overall fracture surface even in hydrogen for the type 304. It cannot be considered that the increase in the faceted area is the main cause of the FCG acceleration in both materials. Concerning the ductile mode, as stated above, it is considered that hydrogen has the effect of FCG acceleration by localization of slip to fatigue crack tip ${ }^{(19)}$ in the slip-off mechanism. Though there is the difference in the degree between the materials, this phenomenon is considered to occur in the case of not only the type 304 but also the type $316 \mathrm{~L}$ stable austenitic stainless steel. It is understood that both the accelerating effects by increasing the brittle facets in the brittle mode and by the localization of slip to fatigue crack tip in the ductile mode are small in the type $316 \mathrm{~L}$ compared with those in the type 304 . This results in the fact that the degree of FCG acceleration in the type 316L is lower than that in the type 304. Also, the latter acceleration effect is considered to be the predominant effect on FCG characteristics in both austenitic stainless steels as the effects of hydrogen environment of no more than about $1 \mathrm{MPa}$.

Though the difference between austenitic stainless steels regarding the formation of a brittle part on the fracture surface has been investigated ${ }^{(12) \sim(16)}$, the cause of the difference in the degree of FCG acceleration between materials in the ductile fracture mode is not obvious. It is postulated that one cause of the hydrogen sensitivity in the ductile mode is based on the difference in the stability of the $\gamma$ phase due to the high hydrogen transportability in strain-induced $\alpha^{\prime}$ martensite phase compared to $\gamma$ austenite phase. The elucidation of the microscopic phenomenon is a next subject.

\section{Conclusion}

In order to clarify the effects of the hydrogen gas environment on the fatigue crack growth characteristics of stable austenitic stainless steels in the range of relatively high fatigue crack growth rates, the bending fatigue tests were carried out on a type $316 \mathrm{~L}$ in a pure dry hydrogen gas, in a pure dry nitrogen gas at $1.0 \mathrm{MPa}$ and in air. Also, the difference in the hydrogen sensitivity between austenitic stainless steels was discussed by comparison of the fatigue crack growth characteristics between the type $316 \mathrm{~L}$ and a type 304 metastable austenitic stainless steel. The obtained main results are as follows.

(1) Hydrogen gas accelerates the fatigue crack growth rate of type $316 \mathrm{~L}$ stable austenitic stainless steel. The degree of the fatigue crack growth acceleration in type $316 \mathrm{~L}$ is low compared to that in type 304 metastable austenitic stainless steel.

(2) The fracture surfaces of both materials practically consist of two parts; the faceted area seemed to be brittle and the remaining area seemed to be ductile. The facets increase somewhat in hydrogen in the case of type 304, though the ratio of the ductile fracture surfaces to the overall fracture surface is high in both environments and in both materials.

(3) The faceted area seemed to be a brittle surface does not significantly contribute to the fatigue crack growth rate in both austenitic stainless steels. The main cause of the fatigue crack growth acceleration of both materials exists in the mechanism forming the remaining surface that seemed to be ductile. The slip-off mechanism seems to be valid not only in air and in nitrogen, but also in hydrogen. The accelerating effect in type $316 \mathrm{~L}$ is lower than that in type 304.

(4) The degree of an acceleration in type $316 \mathrm{~L}$ is lower than that in type 304 because both accelerating effects by an increase in the faceted area in the brittle mode and by localization of slip to fatigue crack tip in the ductile mode in type $316 \mathrm{~L}$ are low compared with those in type 304. Also, the latter effect is considered to be predominant for the fatigue crack growth in both steels as the effects of the hydrogen environment at a low pressure.

Though the hydrogen sensitivity on the fatigue crack growth is considered to be 
concerned with the difference in the stability of the $\gamma$ phase, the elucidation of the microscopic mechanism is the next subject. Fatigue crack growth acceleration in the ductile mode will be evaluated through measurements of strain-induced $\alpha^{\prime}$ martensite distribution and hydrogen local content distribution around a fatigue crack tip and fatigue crack opening displacement range.

\section{Acknowledgement}

The observation of fatigue fracture surfaces was carried out using an SEM at the Center of Advanced Instrumental Analysis, Kyushu University. We are deeply grateful to this organization.

\section{References}

(1) Alexander. R. Troiano, The Role of Hydrogen and Other Interstitials in the Mechanical Behavior of Metals, Transactions of the American Society for Metals, 52 (1960), 54 80 .

(2) C. D. Beachem, A New Model for Hydrogen-Assisted Cracking (Hydrogen "Embrittlement"), Metallurgical Transactions, 3 (1972), 437 - 451.

(3) R. Brazill et al., Fatigue Crack Growth in 2/1/4-Cr-1Mo Steel Exposed to Hydrogen Containing Gases, Journal of Engineering Materials and Technology, 101 (1979), $199-204$.

(4) John P. Hirth, Effects of Hydrogen on the Properties of Iron and Steel, Metallurgical Transactions, 11A (1980), $861-890$.

(5) H. Kimura and H. Matsui, Mechanism of Hydrogen-Induced Softening and Hardening in Iron, Scripta Metallurgica, 21 (1987), 319 - 325.

(6) S. P. Lynch, Environmentally Assisted Cracking - Overview of Evidence for an Adsorption-Induced Localized-Slip Process, Acta Metallurgica， 36 - 10 (1988)， 2639 $-2661$.

(7) Special issue on recent advances in the engineering aspects of hydrogen embrittlement, Engineering Fracture Mechanics, 68 - 10 (1988).

(8) P. J. Ferreira et al., Hydrogen Effects on the Interaction between Dislocations, Acta Metallurgica, 46 - 5 (1998), 1749 - 1757.

(9) Y. Murakami et al., Factors Influencing the Mechanism of Superlong Fatigue Failure in Steels, Fatigue and Fracture of Engineering Materials and Structures, 22 (1999), $581-590$.

(10) R. M. Vennett and G. S. Ansell, The Effect of High-Pressure Hydrogen upon the Tensile Properties and Fracture Behavior of 304L Stainless Steel, Transactions of the American Society for Metals, $\quad \mathbf{6 0}-2$ (1967), 242 - 251.

(11) A. W. Thompson, The Behavior of Sensitized 309S Stainless Steel in Hydrogen, Material Science and Engineering, 14 (1974), 253 - 264.

(12) C. L. Briant, Hydrogen Assisted Cracking of Sensitized 304 Stainless Steel, Metallurgical Transactions, 9A (1978), $731-733$.

(13) C. L. Briant, Hydrogen Assisted Cracking of Type 304 Stainless Steel, Metallurgical Transactions, 10A (1979), 181 - 189.

(14) G. Schuster and C. Alstetter, Fatigue of Stainless Steel in Hydrogen, Metallurgical Transactions, 14A (1983), $2085-2090$.

(15) S. Fukuyama et al., Fatigue Properties of Type 304 Stainless Steel in High Pressure Hydrogen at Room Temperature, Transactions of the Japan Institute of Metals, 26 - 5 (1985), $325-331$.

(16) G. Han et al., Effect of Strain-Induced Martensite on Hydrogen Environment Embrittlement of Sensitized Austenitic Stainless Steel, Acta materialia, 46 - 13 (1998), $4559-4570$ 
(17) M. B. Whiteman and A. R. Troiano, Hydrogen Embrittlement of Austenitic Stainless Steel, Corrosion, 21 (1965), 53 - 56.

(18) M. L Holzworth, Hydrogen Embrittlement of Type 304L Stainless Steel, Corrosion, 25 - 3 (1969), 107 - 115.

(19) Y. Oda and H. Noguchi, Observation of Hydrogen Effects on Fatigue Crack Growth Behaviour in an $18 \mathrm{Cr}-8 \mathrm{Ni}$ Austenitic Stainless Steel, International Journal of Fracture, 132 - 2 (2005), 99 - 113.

(20) Y. Aoki et al., Fatigue Characteristics of a Type 304 Austenitic Stainless Steel in Hydrogen Gas Environment, International Journal of Fracture, 133 - 3 (2005), 277 288.

(21) T. Hirayama and M. Ogirima, Influence of Chemical Composition on Martensitic Transformation in Fe-Cr-Ni Stainless Steel (in Japanese), Journal of the Japan Institute of Metals, 34 - 5 (1970), 507 - 510.

(22) N. M. Grinberg, The Effect of Vacuum on Fatigue Crack Growth, International Journal of Fatigue, 4 - 2 (1982), 83 - 95.

(23) R. M. N. Pelloux, Mechanism of Formation of Ductile Fatigue Striations, Transactions of the American Society for Metals, 62 - 2 (1969), 281 - 285.

(24) P. Neumann, New experiment concerning the slip processes at propagating fatigue cracks -I, Acta Metallurgica, 22 - 9 (1974), 1155 - 1165.

(25) Y. Oda et al., AFM and SEM Observation on Mechanism of Fatigue Crack Growth in an Fe-Si Single Crystal, International Journal of Fracture, 113 - 3 (2002), 213 - 231. 